\title{
Bioactive compounds from Lactarius deterrimus interfere with the invasive potential of gastric cancer cells*
}

\author{
Kamila Król1, Maciej Pudełek1, Gracjana Krzysiek-Mączka², Mateusz Wierdak², \\ Bożena Muszyńska4 ${ }^{4}$ Katarzyna Sułkowska-Ziaja4, Agata Krakowska5, Damian Ryszawy ${ }^{1 \dagger}$ and \\ Jarosław Czyż ${ }^{1 \otimes}$
}

'Department of Cell Biology, Faculty of Biochemistry, Biophysics and Biotechnology, Jagiellonian University, Kraków, Poland; 2Department of Physiology, Faculty of Medicine, Jagiellonian University Medical College, Kraków, Poland; ${ }^{2} 2$ nd Department of General Surgery, Faculty of Medicine, Jagiellonian University Medical College, Kraków, Poland; ${ }^{4}$ agiellonian University Medical College, Faculty of Pharmacy, Department of Pharmaceutical Botany, Kraków, Poland; 5 Jagiellonian University Medical College, Faculty of Pharmacy, Department of Inorganic and Analytical Chemistry, Kraków, Poland

†This paper is dedicated to the memory of Dr. Damian Ryszawy, PI in this project, who suddenly passed away on September 11th, 2020

\begin{abstract}
Stomach cancer is the 4th most common cancer diagnosed worldwide. Despite intensive research on its etiopathology, its treatment strategies have not changed in the last $\mathbf{5 0}$ years. Mushrooms have recently attracted much attention as the source of bioactive compounds that can potentially complement cancer therapies. Here, we extracted a phenolic fraction from Lactarius deterrimus and analyzed its composition and bioactivity against the gastric cancer (AGS) cells. The complexity of $L$. deterrimus compounds was revealed by an HPLC assay, and was accompanied by cytostatic, cytotoxic and anti-invasive effects of the $L$. deterrimus extract (LDE). These are illustrated by inhibition of the AGS cells' proliferation, metabolic activity and motility, and by induction of the cytoskeleton rearrangements. Apparently, these effects are exerted via activation of intracellular oxidative stress and decreased ATP production in AGS cells that could not be compensated by induction of autophagy. Less severe LDE effects were seen on physiology of normal gastric fibroblasts; however, inhibition of their motility indicates that LDE can interfere with gastric cancer development via an effect on stromal cells. Along with the observed synergy of LDE and cisplatin/5-fluorouracil effects on AGS cells, our data show the potential of LDE for supplementation of the gastric cancer therapy.
\end{abstract}

Keywords: Lactarius deterrimus, stomach cancer, AGS, proliferation, motility, chemotherapy

Received: 21 September, 2021; revised: 21 October, 2021; accepted: 21 October, 2021; available on-line: 14 November, 2021

घe-mail: jarek.czyz@uj.edu.pl

*This paper has been published on the occasion of Jubilee Conference entitled "The latest achievements in biochemistry, biophysics and biotechnology - 50 years of history of the Faculty of Biochemistry, Biophysics and Biotechnology of the Jagiellonian University in Kraków" Kraków, September 23-24, 2021

Acknowledgements of Financial Support: This research was funded by the Polish National Science Centre (2015/19/D/NZ3/00273 to D.R) and in part by the Polish Ministry of Science and Higher Education (grant no. 0161/DIA/2019/48 to M.P.)

Abbreviations: cisPt, cisplatin; DMEM, Dulbecco's Modified Eagle's Medium; EDTA, Ethylenediaminetetraacetic acid; F-AAS, flame atomic absorption spectrometry; FBS, fetal bovine serum; 5-FU, 5-fluorouracil; HGFs, Human gastric fibroblasts; Hp, Helicobacter pylori; HPLC-DAD, high-performance liquid chromatography with diode-array detection; IMC, integrated modulation contrast; LDE Lactarius deterrimus extract; MTT, 3-(4;5-dimethylthiazol-2-yl)-2;5- diphenyltetrazolium bromide; NAC, N-Acetyl-L-cysteine; $\mathrm{NCl}$, National Cancer Institute; NK, natural killer; OXPHOS, oxidative phosphorylation; PBS, phosphate buffered saline; PSK, Polysaccharide-K; RFU, relative fluorescence units; ROS, reactive oxygen species; TIRF, total internal reflection fluorescence

\section{INTRODUCTION}

Despite of progress in the prophylactics, diagnosis and treatment of gastric cancer, its incidence is still relatively high (Global Challenges of cancer, Nature Cancer, 2020), which makes it the third most common cause of cancerrelated deaths in 2018 (Bray et al., 2018). High incidence of gastric cancer is observed in the populations of East Asia, Eastern Europe and some regions of Central and South America (Brenner et al., 2009), where the 5-years survival rate of gastric cancer patients reaches only $31.5 \%$. It is more frequently diagnosed among men and its frequency raises with the age of the patient. These facts have attracted much attention to the role of environmental factors in the gastric cancer development. Apparently, they increase the risk of its initiation and presumably include unbalanced diet (high salt content, alcohol), smoking and bacterial infections (especially Helicobacter pylori) (You et al., 1988; Brenner et al., 2009). Even though $H$. pylori infections are now effectively eliminated, surgical resection of the tumor, followed by chemotherapy and/or radiotherapy, is a primary treatment standard against this tumor. However, cytostatics implemented in gastric cancer treatment, i.e. 5-fluorouracil, docetaxel, irinotecan or cisplatin, must generally be applied for the rest of the patient's life (NCI's cancer drug information). Nowadays, several targeted therapies received licenses for gastric cancer treatment, which include application of ramucirumab and trastuzumab (Smyth et al., 2020). Concomitantly, naturally occurring substances (probiotics and symbiotics) have been identified to enhance the efficiency of chemotherapy in clinical trials (Sobolewska et al., 2021).

Due to the adverse effects of these agents, alternative therapies are desirable, particularly those based on metronomic/combined approaches. The location and function of the stomach results in a relatively high bioavailability of orally supplied compounds in the proximity of gastric cancer niches. This prompts implementa- 
tion of natural substances in its chemotherapy (Passamonti et al., 2003; Marchand, 2002; Song et al., 2020). Their main sources include plants, snake venoms, frog/ snail toxins and lichens (Hashemi et al., 2011; Jain et al., 2012; Gomes et al., 2010; Shrestha et al., 2013). In this context, research on the potential of fungi is considerably less intense, even though these organisms are relatively rich in steroids, terpenes, fatty acids, alkaloids, phenolics, flavonoids, lectins and vitamins (Rayan et al., 2017; Sułkowska-Ziaja et al., 2017, Lichota \& Gwozdzinski, 2018; Ijaz et al., 2018). Pharmacokinetic studies on fungi, which have been mostly performed in the Asian countries, suggest their therapeutic potential that justifies their application in anti-diabetic, anti-bacterial, cardioprotective, immunomodulating and anti-tumor treatment strategies (Chatterjee et al., 2017). For instance, Coriolus versicolor fruiting bodies contain polysaccharide $\mathrm{K}$ (PSK), which was shown in vitro, in vivo and in clinical trials to act directly on the colon and breast cancer cells, and to stimulate the patient's immune cells. Consequently, PSK application can increase the 5-year survival rate of patients (a 9\% absolute reduction in mortality) (Tsukagoshi et al., 1984; Habtemariam, 2020). However, still little is known on the anti-cancer properties of European fungi.

Lactarius deterrimus is an edible mushroom of the Russulaceae family. It is widespread in Europe, where it lives in forests and forms mycorrhizae with spruce (Giollant et al., 1993). Its fruiting bodies are characterized by orangish caps with green spots and they normally secrete light-orange latex after injury (Nuytinck, 2005). Previous research showed that $L$. deterrimus extracts are rich in sesquiterpenes (Bergendorff \& Sterner, 1988), lectins (Giollant et al., 1993) and indole compounds (Muszyńska, 2007). Apparently, these compounds are responsible for L. deterrimus antioxidative potential (Sarikurkcu et al., 2008), protective effects against streptozotocin-induced oxidative stress and pancreatic $\beta$-cell death (Grdović et al., 2012; Mihailović et al., 2015), and antimicrobial activity (Dulger et al., 2002). However, anti-cancer activity of $L$. deterrimus compounds has not been addressed so far. In this study, we filled this gap by focusing on the anticancer properties of $L$. deterrimus compounds. In particular, we tested the effects of the $L$. deterrimus extract (LDE) on the viability/invasive potential of gastric cancer cells, scrutinized the mechanisms underlying these effects and analyzed the synergy of LDE activity with conventional chemotherapeutics.

\section{MATERIALS AND METHODS}

\section{Preparation and characterization of ethanol extracts from $L$. deterrimus}

The fruiting bodies of Lactarius deterrimus were harvested in its natural environment $\left(49^{\circ} 85^{\prime} 41.99^{\prime}\right.$ N $\mathrm{N}$, $\left.19^{\circ} 73^{\prime} 56.26^{\prime \prime} \mathrm{E}\right)$. Samples were dried at $50^{\circ} \mathrm{C}$ for 12 hours in an MPM MSG-01 dryer and shredded with mortar and pestle. EtOH (99.7\%; Merck, Darmstadt, Germany) was used as a solvent for extraction. 2 grams of the mushroom powder were stored in $\mathrm{EtOH}$ for 24 hours (at room temperature, in darkness/airtight glass bottle). Then, the solution was centrifuged at $4000 \mathrm{~g}$ for 10 minutes (5804 Centrifuge; Eppendorf), and the supernatant was collected and evaporated in a water bath (to $0.12 \mathrm{~g}$ of the dry mass). The extract was diluted in $99.7 \%$ ethanol to obtain stock solutions of the Lactarius deterrimus extract (LDE; $50 \mathrm{mg} / \mathrm{ml}$ ). The final LDE con- centrations ranging from 50 to $200 \mu \mathrm{g} / \mathrm{ml}$ of the culture medium were tested in the experiments.

\section{Cell cultures}

Human stomach cancer AGS cells (ATCC, CRL1739) were cultured under standard conditions $\left(5 \% \mathrm{CO}_{2}\right.$, $37^{\circ} \mathrm{C}$ ) in RPMI/F12 complete medium (Sigma), supplemented with 10\% fetal bovine serum (FBS; Gibco) and 1\% Antibiotic-Antimycotic Solution (Sigma). For their propagation, the cells were harvested with $\mathrm{Ca}^{2+} / \mathrm{Mg}^{2+}$ free PBS (Corning) supplemented with $0.5 \mathrm{mM}$ EDTA (UltraPure ${ }^{\mathrm{TM}}$; Invitrogen), counted with the Z2 particle counter (Beckman Coulter) and seeded into (multi-well) tissue culture plates (Eppendorf). Human gastric fibroblasts (HGFs) were isolated from human gastric biopsies of patients free of systemic inflammatory diseases and Helicobacter pylori $(\mathrm{Hp})$ infection. The patients were qualified for laparoscopic sleeve gastrectomy at the Department of Endoscopic, Metabolic and Soft Tissue Malignancies Surgery, the Jagiellonian University Medical College in Cracow. Gastric biopsies were minced into $1-2 \mathrm{~mm}^{3}$ pieces and placed in sterile tissue culture flasks in DMEM supplemented with $10 \%$ fetal bovine serum (FBS, Sigma) and antibiotics. The flasks were maintained in a humidified atmosphere $\left(5 \% \mathrm{CO}_{2}\right.$ at $\left.37^{\circ} \mathrm{C}\right)$ and the medium was changed every 2 days. At $80 \%$ confluence, the cultures were detached with a standard trypsinization technique to establish a secondary cell culture. For endpoint experiments, cells were seeded into (multi-well) tissue culture plates (Eppendorf), cultivated for 24 hours before administration of the medium supplemented with LDE $(50-200 \mu \mathrm{g} / \mathrm{ml})$, cytostatic drugs - cisplatin (cisPt; Sigma; No. 400033; $1 \mu \mathrm{g} / \mathrm{ml}$ ) and 5-fluorouracil (5-FU; Sigma; No. F6627 $10 \mu \mathrm{M})$, and N-Acetyl-L-cysteine (NAC; Sigma; No. A9165; $1 \mathrm{mM}$ ). Experiments were approved by a local ethics commission (Decision No. 1072.6120.263.2020).

\section{Cell proliferation and viability}

Cells were seeded into 12 - or 24 -well plates (Eppendorf) at a density of $1 \times 10^{4}$ cells $/ \mathrm{cm}^{2}$, incubated for 24 hours before addition of the LDE-supplemented medium (50-200 $\mu \mathrm{g} / \mathrm{ml}$ ) and/or 5-fluorouracil/cisplatin. Every 24 hours, the cells were harvested and counted with the Z2 particle counter (Coulter). The data were processed with the Origin Pro 2016 software to calculate the population doubling times. Cell viability was estimated with the Trypan blue (Sigma; No. T8154) assay using a Būrker chamber as described before (Ryszawy et al., 2019a). MTT assay was applied to estimate relative rates of metabolic activity. Cells were seeded into 96-well plate (Eppendorf) at a density of $5 \times 10^{3} /$ well, treated with appropriate agents for 48 hours, and followed by incubation with the thiazolyl blue tetrazolium bromide (Sigma; No. M5655) solution in water $(0.5 \mathrm{mg} / \mathrm{ml})$ for 2-3 hours at $37^{\circ} \mathrm{C}$. Subsequently, the cells were imaged using the Leica DMI6000B microscope to visualize the intracellular accumulation of formazan, followed by dissolution of each well content with isopropanol. Absorbance of the reaction product was measured at $570 \mathrm{~nm}$ (Multiskan $^{\text {TM }}$ FC Microplate Reader; Thermo Fisher Scientific).

\section{Cell migration}

Cells were seeded and treated as described above. 24 hours after extract/cisplatin/5-fluorouracil/NAC administration, time-lapse imaging of their movement was 
performed (Sroka et al., 2007; Ryszawy et al., 2019b). Briefly, cell images were recorded for 8 hours with 5 min time interval using the Leica DMI6000B microscope equipped with integrated modulation contrast (IMC) optics and $\mathrm{CO}_{2}\left(\sim 5^{\circ}\right) /$ temperature $\left(37^{\circ} \mathrm{C}\right)$ chamber. Sequences of images were further analyzed with the Hiro v.1.0.0.4 software (written by W. Czapla) by manual cell trajectory tracking, followed by calculation of cell motility parameters: speed of cell motility $[\mathrm{V} ; \mu \mathrm{m} / \mathrm{min}]$ and cell displacement $[\mathrm{D} ; \mu \mathrm{m}])$.

\section{Immunocytochemistry}

For immunofluorescence studies, the cells were treated with LDE and/or cisplatin/5-fluorouracil for 48 hours in 12-well plates on UVC-sterilized coverslips. Then, they were fixed with $3.7 \%$ formaldehyde and permeabilized with $0.1 \%$ Triton X-100. Blocking of non-specific binding sites was performed with $2 \%$ BSA (30-45 min. in $37^{\circ} \mathrm{C}$ ), followed by cell incubation in the presence of mouse monoclonal anti-vinculin IgG (Sigma; No. V9131; 1:300; 45 min.) diluted in 2\% BSA $/ 0.01 \%$ Tween. Then, AlexaFluor488-conjugated donkey anti-mouse IgG (Invitrogen; No. A21202), AlexaFluor546-conjugated phalloidin (Invitrogen, No. A22283; F-actin visualization) and Hoechst 33258 (Sigma; for DNA staining) were applied for $45 \mathrm{~min}$. Images were acquired with the Leica DMI6000B fluorescence microscope equipped with DFC360FX CCD camera and total internal reflection fluorescence (TIRF) module. Raw photos were further processed (contrast adjustment, background subtraction) with the ImageJ software (Pudełek et al., 2019).

\section{Autophagy}

Cells were seeded into fluorescence imaging-dedicated 24-well plates (Eppendorf, No. 0030741005) at a density of $10^{4}$ cells $/ \mathrm{cm}^{2}$, treated with LDE for 2-48 hours, incubated with Detection Reagent (Autophagy level determination kit; Sigma; No. MAK138) according to the manufacturer's recommendation and examined with the Leica DMI6000B microscope in the presence of $5 \%$ $\mathrm{CO}_{2} / 37^{\circ} \mathrm{C}$. For each specimen, pictures from at least 10 randomly chosen areas $(\mathrm{N}>30)$ were taken for fluorimetric analysis (fluorescence intensity, background subtraction) performed with the ImageJ software.

\section{Mitochondrial ROS production and membrane potential measurements}

Cells were seeded into fluorescence imaging-dedicated 24-well plates (Eppendorf, No. 0030741005) and treated with LDE for 24 hours. For the analyses of mitochondrial ROS levels, the cells were incubated with 1 $\mu \mathrm{l} / \mathrm{ml}$ of CellROX Orange Reagent (Invitrogen; No. C10443) for $30 \mathrm{~min}$, followed by the application of FluoroBrite $^{\text {TM }}$ DMEM (Gibco; supplemented with 10\% FBS and $1 \%$ GlutaMax). Images were acquired with the Leica DMI6000B microscope (ex. $546 \mathrm{~nm}$ ) in $5 \% \mathrm{CO}_{2} / 37^{\circ} \mathrm{C}$. Fluorimetric analysis (fluorescence intensity, background subtraction) was performed with the ImageJ software. For the analyses of the mitochondrial membrane potential, the cells were incubated with $2 \mu \mathrm{M}$ JC-1 (Thermo Fisher Scientific; No. T3168) in $37^{\circ} \mathrm{C} / 5 \% \mathrm{CO}_{2}$ for 20 minutes, washed with PBS and immersed in FluoroBrite TM DMEM (Gibco; supplemented with 10\% FBS and 1\% GlutaMax (Pudełek et al., 2019)). Signal detection was performed using the Leica DMI6000B microscope.

\section{Calcium flux detection}

Cells were seeded into cell imaging dishes (Eppendorf, Cat. No. 0030740009) at a density of $1.5 \times 10^{4}$ cells $/ \mathrm{cm}^{2}$ and cultivated for 24 hours. Afterwards, the cells were incubated with Fluo-4 AM $(2 \mu \mathrm{M})$ for 30 minutes and standard culture medium was replaced with FluoroBrite $^{\text {TM }}$ DMEM as described above. Analysis was performed with time-lapse module (10s time step, $11 \mathrm{~min}$ ) using the Leica DMI6000B microscope (ex. $546 \mathrm{~nm}$ ) equipped with $\mathrm{CO}_{2}(5 \%)$ chamber and temperature $\left(37^{\circ} \mathrm{C}\right)$ stabilizing system. Cells were exposed to single dose of LDE (final concentration $200 \mu \mathrm{g} / \mathrm{ml}$ ) or $0.02 \%$ EtOH (vehicle control). The images were processed with the LAS $\mathrm{X}$ and ImageJ software to calculate the relative change of fluo-4 fluorescence intensity $(\triangle \mathrm{RFU})$.

\section{HPLC-DAD analysis}

Identification of phenolic compounds was performed according to the procedure described previously (Ziaja et al., 2017). HPLC analyses were performed using a Hitachi HPLC VWR apparatus: L-2130 pump, RP-18e column $(250 \times 4 \mathrm{~mm}, 5 \mu \mathrm{m})$ thermostated at $25^{\circ} \mathrm{C}$ and a diode array detector (DAD) L-2455 in the UV range 200-400 $\mathrm{nm}$. The gradient program was as follows: $0-20$ min., 0\% B; 20-35 min, 0-20\% B; 35-45 min, 20-30\% B; 45-55 min, 30-40\% B; 55-60 min., 40-50\% B, 60-65 min., 50-75\% B; and 65-70 min., 75-100\% B, with a hold time of $15 \mathrm{~min}$., at $25^{\circ} \mathrm{C}$. The flow rate was 1.0 $\mathrm{mL} / \mathrm{min}$. Comparison of the UV spectra at $\lambda=254 \mathrm{~nm}$ and the retention times with the standard compounds allowed for identification of phenolic acids present in the analyzed samples. Phenolic acid standards were purchased from Fluka (Chemie AG) and Sigma (St. Louis, USA).

Identification of sterols was performed according to the procedure developed by Yuan (Yuan et al., 2008) with some modifications to the gradient procedure. The mobile phase consisted of solvent A: methanol/water 80:20 (v/v) and solvent B: methanol/dichloromethane $75: 25(\mathrm{v} / \mathrm{v})$. The gradient program was as follows: 0-10 min, 80: 20\% B; 10-35 min, 40-60\% B; 35-50 min, 0-100\% B; 50-55 min, 80-20\% B; with a hold time of $15 \mathrm{~min}$ at $25^{\circ} \mathrm{C}$. The flow rate was $1.0 \mathrm{~mL} /$ min. Chromatographic peaks were recorded at a wavelength of $280 \mathrm{~nm}$. Sterol standards were purchased from Fluka (Chemie AG).

Identification of indole compounds was performed according to the procedure described by Muszyńska (Muszyńska et al., 2020). Briefly, the conditions were as follows: Hitachi HPLC; pump L-7100; Purospher RP-18 column $(250 \times 4 \mathrm{~mm}, 5 \mu \mathrm{m})$. An isocratic separation was used, and the mobile phase was methanol:water:ammonium acetate 15:14:1 (v/v/v); flow $1 \mathrm{~mL} / \mathrm{min}$. The chromatographic peaks were recorded at a wavelength of $280 \mathrm{~nm}$. Indole standards were purchased from Sigma (St. Louis, USA).

\section{F-AAS analysis of bioelements}

For mineralization, ethanol extract of $L$. deterrimus was transferred to Teflon vessels, to which $2 \mathrm{~mL}$ of $30 \% \quad \mathrm{H}_{2} \mathrm{O}_{2}$ solution (Merck, Darmstadt, Germany) and $4 \mathrm{~mL}$ of concentrated $65 \% \mathrm{HNO}_{3}$ solution were added (Merck, Darmstadt, Germany). Mineralization was carried out in a Magnum II microwave apparatus (ERTEC) in three stages, each for $10 \mathrm{~min}$, at a power of $70 \%$ and $100 \%$, respectively, maintaining the temperature of the device at $290^{\circ} \mathrm{C}$. After mineralization, 
the solutions were transferred to quartz evaporators and evaporated on a heating plate at $150^{\circ} \mathrm{C}$ to remove excess reagents and water. The residue was quantitatively transferred to $10 \mathrm{~mL}$ volumetric flasks with fourtime-distilled water. Bioelement analysis was carried out using flame atomic absorption spectroscopy (F-AAS) with an AAS iCE3300 Thermo Scientific ${ }^{\text {TM }}$ spectrophotometer (UK).

\section{Statistical analysis}

Statistical analysis was performed with data from at least 3 independent experiments $(\mathrm{N}>3)$ with the OriginPro 2016 software using ANOVA/non-parametric Mann-Whitney $U$ test $(* P<0.05$; error bars illustrate SEM) or with Statgraphics Centurion XVIII (for LDE content analysis).

\section{RESULTS}

\section{LDE exerts cytostatic effects in gastric stomach AGS model in vitro}

Generally, anti-cancer agents are expected to selectively interfere with the welfare of cancer cells. Therefore, our initial analyses were aimed at estimating the dosedependent Lactarius deterrimus extract (LDE) effects on the viability of gastric cancer AGS cells. A dose-dependent attenuation of these cells' metabolism was illustrated by the ATP and MT'T assay in the presence of LDE (Fig. 1A). Concomitant studies of AGS growth kinetics showed inhibition of AGS proliferation in the presence of LDE administered at the concentration of $200 \mu \mathrm{g} / \mathrm{ml}$ (Fig. 1B). This is also illustrated by comparison of the doubling time/growth rate of control and LDE-treated cells (Fig. 1C). Microscopic analyses showed noticeable transition of the AGS cells towards a spindle-shape morphology in the presence of LDE (Fig. 1D). This was accompanied by vacuolization of the LDE-treated cells. Collectively, our data indicate that LDE exerts a considerable cytotoxic stress in AGS cells that is not compensated by autophagy.

\section{LDE impairs invasiveness of AGS cell in a ROS-dependent manner}

Stomach cancer may spread systemically via lymph nodes and blood vessels. The most common sites of metastasis are liver, peritoneum, lungs and bones (Riihimäki et al., 2016). To verify the significance of cytostatic LDE effects and their consequences for gastric tumor progression, we further concentrated on the anti-invasive properties of LDE. For this purpose, motility of AGS cells was analyzed with time-lapse videomicroscopy, beginning 24 hours after LDE administration (Fig. 2). An inhibitory effect of $\mathrm{LDE}$ on this parameter was illustrated at the single cell (Fig. 2A) and population levels (Fig. 2B) by considerably lower values of averaged speed and cell displacement in the presence of LDE. Approximately 60\% decrease in AGS motility was observed in the presence of $200 \mu \mathrm{M}$ LDE, whereas LDE reduced AGS displacement by ca $40 \%$. These effects were correlated with acquisition of spindle shapes and remodeling/disruption of microfilaments in AGS cells under LDE stress (Fig. 2C). Also, the LDE-induced inhibition of AGS proliferation (Fig. 1) and motility was accompanied by ROS up-regulation. This is illustrated by increased ROS levels in the LDE-treated AGS cells (Fig. 2D). Collectively, these data indicate that the cytostatic and anti-invasive effects of
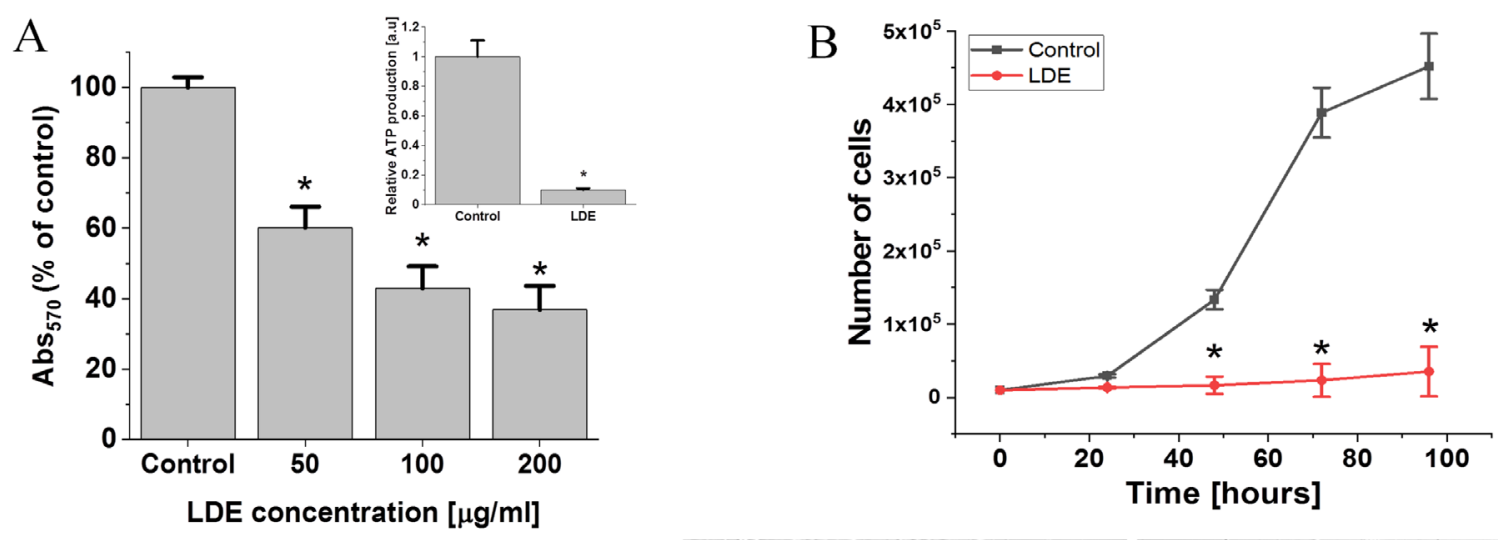

\begin{tabular}{ccc} 
C & Doubling time [h] & Growth rate \\
\hline Control & $23.9 \pm 3.6$ & $0.29 \pm 0.09$ \\
\hline LDE & $52 \pm 7.2^{*}$ & $0.13 \pm 0.04^{*}$
\end{tabular}
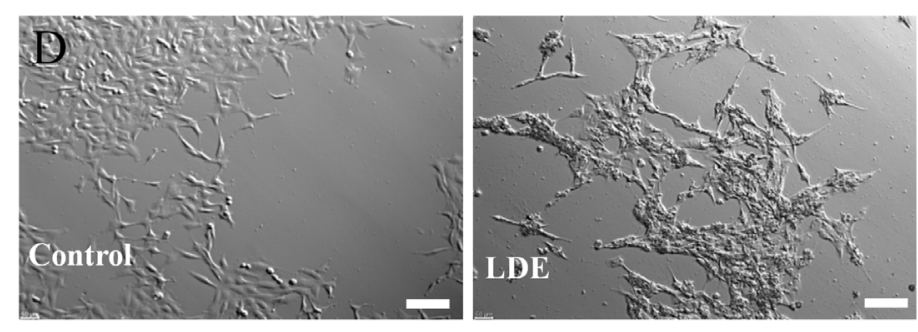

Figure 1. Cytostatic effects of LDE on human gastric cancer AGS cells.

(A) Viability of AGS cells under LDE treatment estimated with Trypan blue and ATP assay (insert). (B) AGS cells were incubated in the presence of $200 \mu \mathrm{g} / \mathrm{ml} \mathrm{LDE}$. Their proliferation was estimated in the next 24-96 hours with Coulter Counter to calculate the population doubling times (C). (D) Morphology of AGS under control conditions (left) and in the presence of $200 \mu \mathrm{g} / \mathrm{ml} \mathrm{LDE}$. Scale bar - $100 \mu \mathrm{m}$. Statistical significance was calculated with ANOVA/non-parametric Mann-Whitney test, ${ }^{*} p<0.05$ vs control. Data representative for 3 independent experiments. Note the inhibitory effect of LDE on the viability and proliferation of gastric cancer cells. 

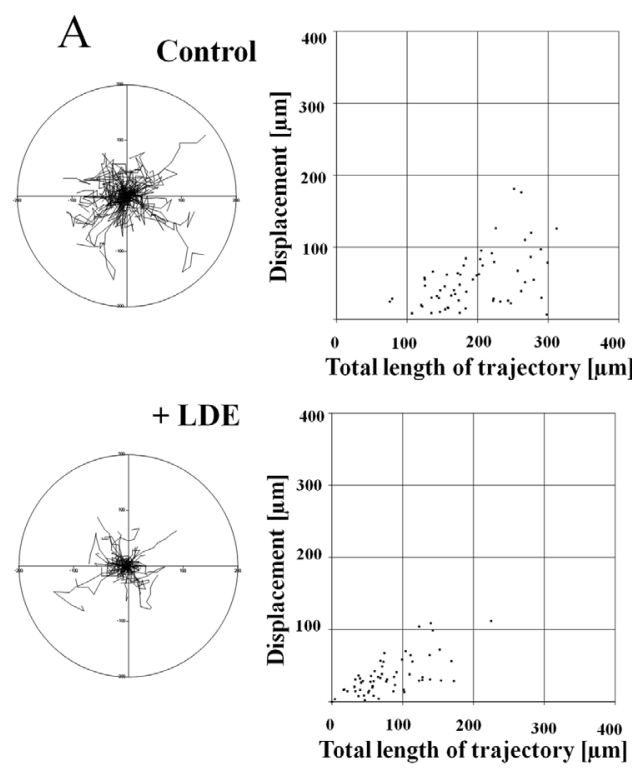
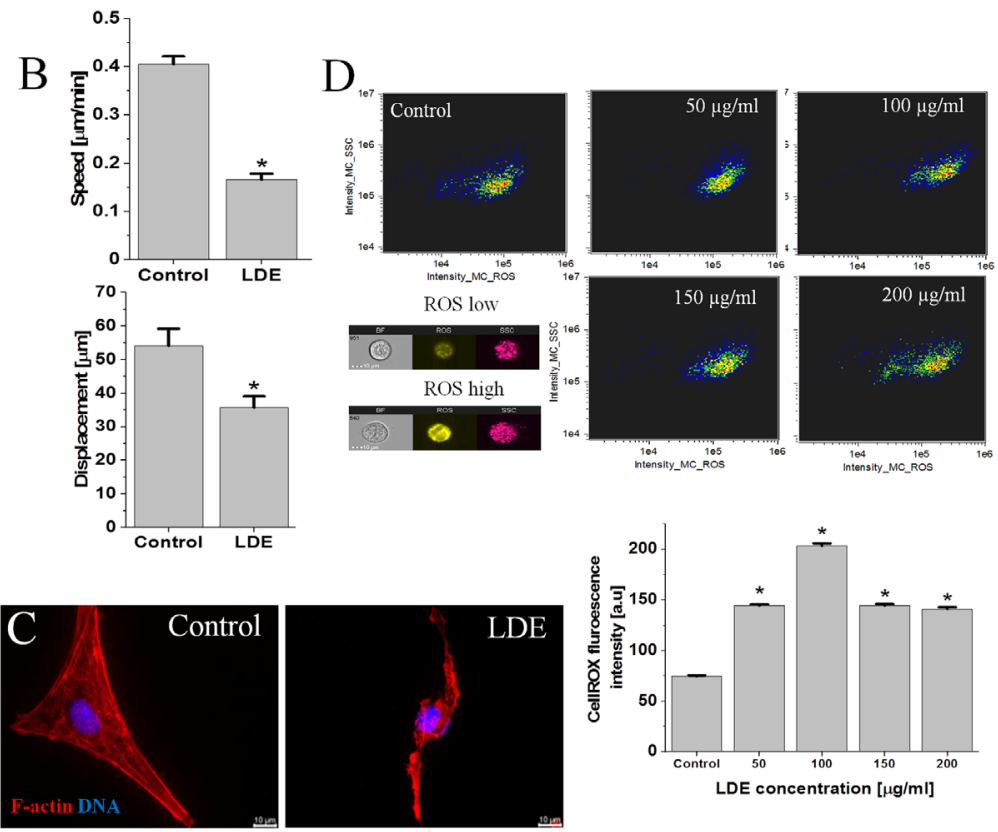

Figure 2. Effect of LDE on the motility, morphology and ROS levels in AGS cells.

(A) AGS cells were seeded at a density of 2000 cells/well into 12-well plates and incubated for 24 hours before administration of 200 $\mu \mathrm{g} / \mathrm{ml} \mathrm{LDE}$. Their motility was estimated with time-lapse video microscopy after 24 hours of incubation in the presence of LDE. Circular diagrams and dot-plots show trajectories and movement parameters (Displacement and total lengths of cell trajectories) of single cells.

(B) Averaged movement parameters of AGS cells (Speed of movement and Displacement) under LDE stress. (C) AGS cells were incubated in the presence of $200 \mu \mathrm{g} / \mathrm{ml} \mathrm{LDE}$ for 48 hours and stained against actin (red)/DNA (blue). (D) Cells were treated with 50-200 $\mu \mathrm{g} / \mathrm{ml}$ LDE

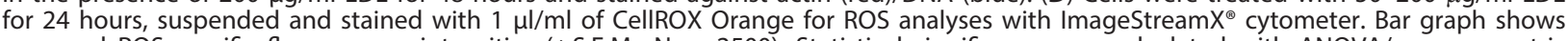
averaged ROS-specific fluorescence intensities ( \pm S.E.M.; $N_{\text {cells }}>2500$ ). Statistical significance was calculated with ANOVA/non-parametric Mann-Whitney test, ${ }^{*} p<0.05$ vs control. Data representative for 3 independent experiments. Note the correlation between inhibited cell motility and ROS up-regulation.

LDE in the AGS model are related to the ROS-dependent mechanism(s).

\section{Autophagy is induced in LDE-treated AGS cells}

Further studies were performed to gain insight into the mechanisms of AGS self-defense responses to the cytostatic/pro-oxidative LDE-induced stress. Autophagy is a natural process that helps the cells to remove damaged or unnecessary components of the cytoplasm. It is a regular response of tumor cells that enables them to withstand and survive the cytostatic stress (Li et al., 2017), whereas excessive autophagy typically results in cell death. In fact, quantification of this process by immunofluorescence-assisted fluorimetry demonstrated a continuously intensifying autophagy in AGS cells treated with $200 \mu \mathrm{g} / \mathrm{ml} \mathrm{LDE}$ (Fig. 3). The intensity of this process in the AGS cells decreased after 72 hours of LDE treatment. In conjunction with the data on cell viability (Fig. 1A), this observation indicates that autophagic cell death is induced by LDE.

\section{Cytostatic LDE properties are related to mitochondrial stress}

LDE-induced ROS production and suicidal autophagy of LDE-treated AGS cells prompted us to
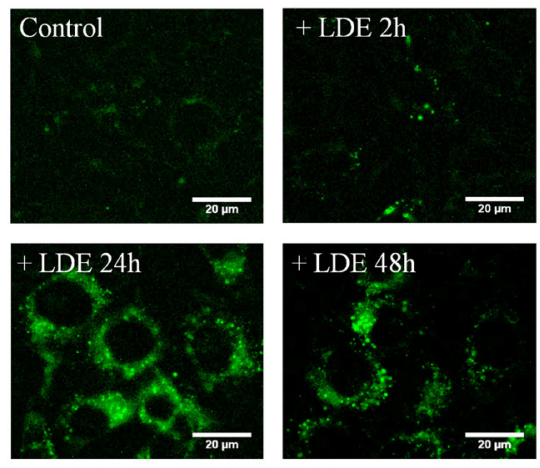

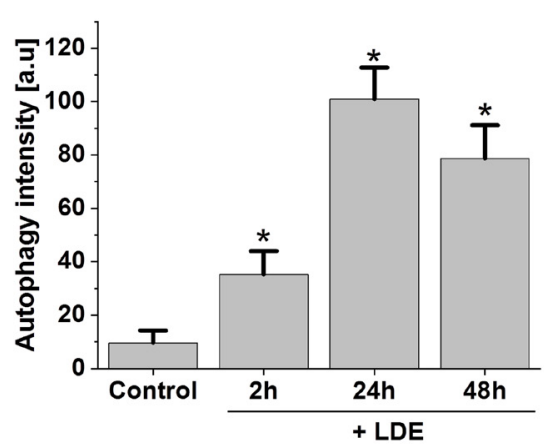

Figure 3. LDE induces a transient autophagic response in AGS cells.

AGS cells were cultivated in the presence of $200 \mu \mathrm{g} / \mathrm{ml}$ LDE for $2,24,48$ and 72 hours, and the intensity of autophagy was estimated at these time-points with the autophagy level determination kit and the microscope - assisted fluorimetry. Scale bar - $25 \mu \mathrm{m}$. Statistical significance was calculated with ANOVA/non-parametric Mann-Whitney test, ${ }^{*} p<0.05$ vs control. Data representative for 3 independent experiments. Note that LDE-induced autophagy correlates with the reduced viability of LDE-treated AGS cells (cf. Fig. 1). 

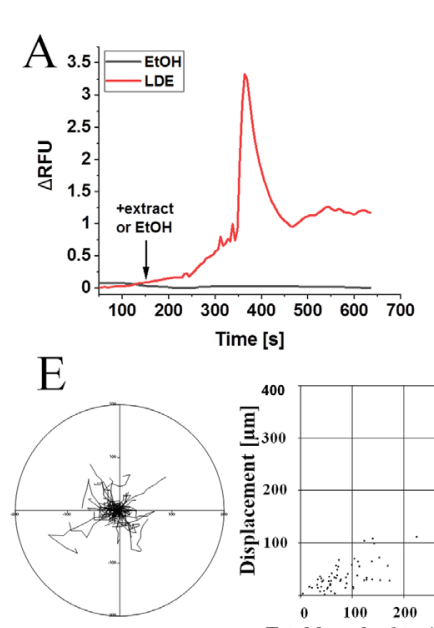

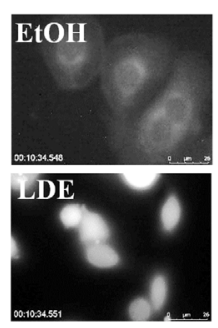

LDE
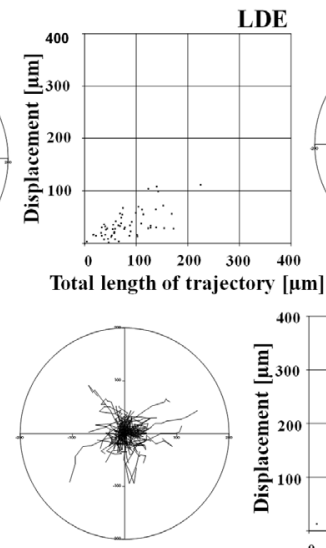

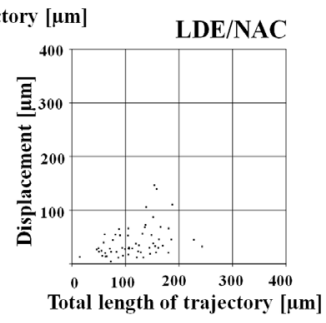

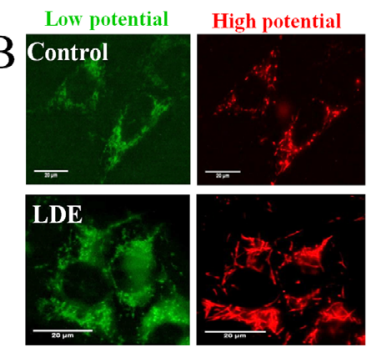

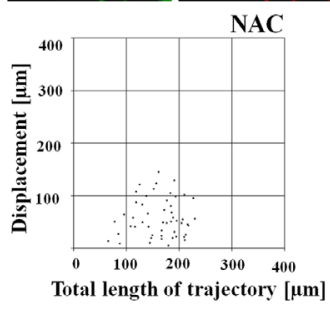

F 0.5

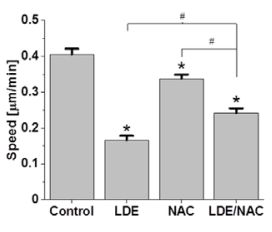

$\mathrm{C}$

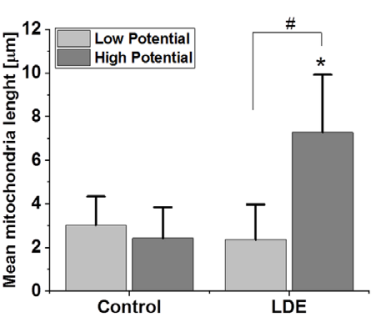

$\mathrm{D}$
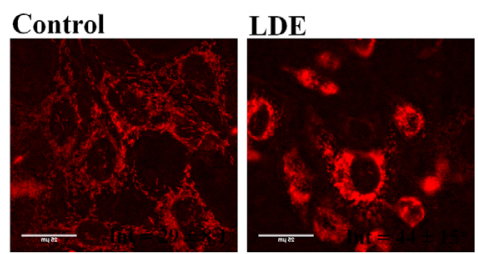

Figure 4. Effect of LDE on the mitochondrial welfare in AGS cells.

(A) AGS cells were seeded at a density of 2000 cells $/ \mathrm{cm}^{2}$ cultivated for 24 hours, stained with Fluo-4, before administration of 200 $\mu$ g/ $\mathrm{ml}$ LDE. Relative cytosolic Ca ${ }^{2+}$ concentrations were then estimated with microscopy-assisted fluorimetric approach. Scale bar - $25 \mu \mathrm{m}$. (B) Cells were treated with $200 \mu \mathrm{g} / \mathrm{ml}$ LDE and stained with MITOX to visualize mitochondrial membrane potential. Scale bar - 50 $\mu \mathrm{m}$. (C) Correlation between the potential and the length of mitochondria. Averaged lengths of mitochondria were estimated with morphometric approach. (D) LDE-treated cells were incubated with $1 \mu \mathrm{l} / \mathrm{ml}$ of CellROX Orange. Images of mitochondrial ROS were acquired with the Leica DMI6000B microscope and analyzed with ImageJ software. (E) AGS cells were seeded at a density of 2000 cells/well in 12 -well plates and incubated for 24 hours before administration of $200 \mu \mathrm{g} / \mathrm{ml}$ LDE and/or 5 mM NAC. Their motility was estimated with timelapse video microscopy. Circular diagrams and dot-plots show trajectories and movement parameters (distance and displacement) at a single cell level. (F) Averaged movement parameters of AGS cells under LDE stress. Statistical significance was calculated with ANOVA/ non-parametric Mann-Whitney test, ${ }^{*} p<0.05$ vs control. Data representative for 3 independent experiments. Note that NAC interferes with the LDE-induced inhibition of AGS motility.

focus on the mechanisms underlying their excessive ROS production. Mitochondrial dysfunction is often a source of ROS; therefore it might also account for oxidative stress in AGS cells subjected to LDE. In fact, our fluorimetric assays demonstrated an instant induction of calcium levels upon addition of LDE $(200 \mu \mathrm{g} / \mathrm{ml})$, whereas a corresponding amount of the EtOH vehicle $(2 \% 0)$ had no effect on the calcium fluxes in the AGS cells (Fig. 4A). Subsequent analysis of the mitochondrial morphology revealed signs of mitochondrial fusion/lengthening in the LDE-treated cells. They are characteristic for the mitochondrial stress and accompanied by increased potential of mitochondrial membranes (Fig. 4B, C). Further tests revealed an induction of the ROS production in the mitochondria of LDE-treated cells (Fig. 4D), whereas ROS scavenging by NAC (N-acetyl-L-cysteine) reduced AGS reactivity to LDE. This is illustrated by time-lapse studies of AGS motility (Fig. 4E), which revealed relatively high AGS displacement in the presence of NAC/LDE, even though migration of the NAC/LDE-treated cells was still lower than that of control cells (Fig. 4F). These data indicate that LDE exerts its cytostatic effects predominantly through induction of mitochondrial dysfunction and oxidative stress.

\section{LDE attenuates proliferation and motility of human gastric fibroblasts}

To further examine therapeutic potential of LDE, we focused on reactivity of the human gastric fibroblasts (HGFs) to LDE. These studies demonstrated an inhibitory effect of LDE on HGF proliferation (Fig. 5A), in the absence of any considerable inhibitory effect on their viability (Fig. 5B). This was accompanied by shifts in LDE-treated HGF morphology towards non-polarized/ spindle-like shapes (Fig. 5C, D) and by inhibition of HGF motility (Fig. 5E). These data show that normal cells are still susceptible to the LDE action, even though the magnitude of HGF reactions to LDE was considerably lower than the one revealed for AGS cells. Due to a possible role of these cells in gastric cancer development, these cytostatic effects may additionally interfere with gastric cancer homeostasis, contributing to the potential of LDE in gastric cancer treatment.

\section{LDE contains an array of anticancer compounds}

Further analyses were performed to identify the compounds responsible for the cytostatic effects of LDE. HPLC analyses showed the presence of numerous organic compounds and bioelements in $L$. deterrimus fruiting bodies (Table 1). For instance, we detected the presence of 3 indoles: L-tryptophan, tryptamine and 
A
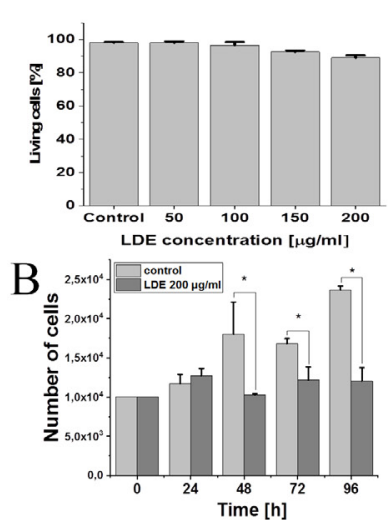
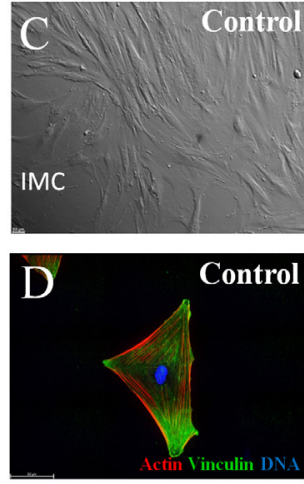

$\mathrm{E}$

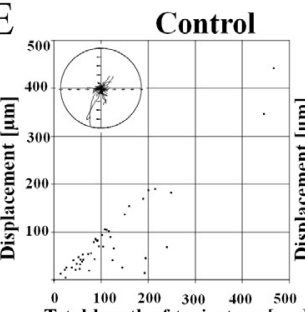
$\begin{array}{lllll}0 & 100 \quad 200 & 300 & 400 \quad 500 \\ \text { Total length of trajectory } & {[\mu \mathrm{m}]}\end{array}$ 0.3
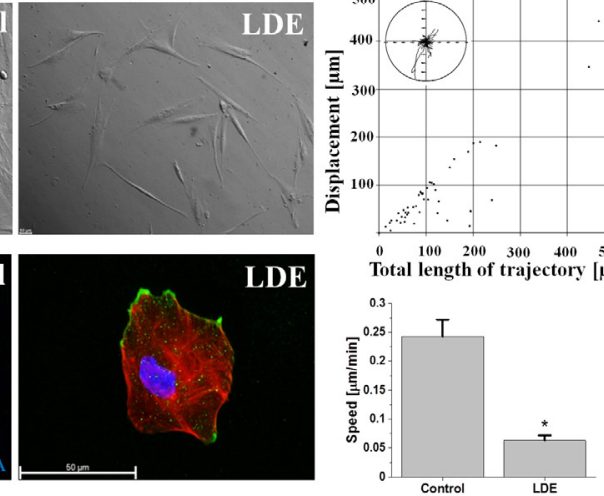

LDE
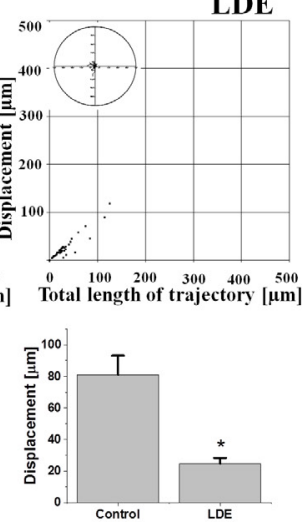

Figure 5. Cytostatic effects of LDE on human gastric fibroblasts (HGFs).

(A) Dose-dependence of HGF survival under LDE stress estimated with Trypan blue assay. (B) HGFs were incubated in the presence of $200 \mathrm{\mu g} / \mathrm{ml}$ LDE. Their proliferation was estimated in the next 24-96 hours with Coulter Counter. (C-D) Morphology and cytoskeleton architecture of HGFs in control conditions (left) and in the presence of $200 \mu \mathrm{g} / \mathrm{ml} \mathrm{LDE}$. (E) HGFs were seeded at a density of 2000 cells/ well in 12-well plates and incubated for 24 hours before administration of $200 \mu \mathrm{g} / \mathrm{ml}$ LDE. Their motility was estimated with time-lapse video microscopy. Circular diagrams and dot-plots show trajectories and movement parameters (distance and displacement) at a single cell level. Bar graphs show averaged movement parameters of AGS cells under LDE stress. Scale bar - $50 \mu$ m. Statistical significance was calculated with ANOVA/non-parametric Mann-Whitney test, ${ }^{*} p<0.05$ vs control. Data representative for 3 independent experiments. Note the inhibitory effect of LDE on proliferation and motility of gastric fibroblasts.

5-hydroxy-L-tryptophan, which are precursors of neurotransmitters: melatonin and serotonin (Muszyńska et al., 2015). This finding confirms the nutritional value of LDE. Among the potentially anti-cancer compounds, we detected an array of phenolic compounds and ster- ols. These include considerable amounts of p-hydroxybenzoic-acid, phenylalanine, cinnamic acid and catechin in LDE. Another group of organic LDE compounds are sterols that include ergosterol and ergosterol peroxide (Kang et al., 2015; Tan et al., 2017). Dry fruit-
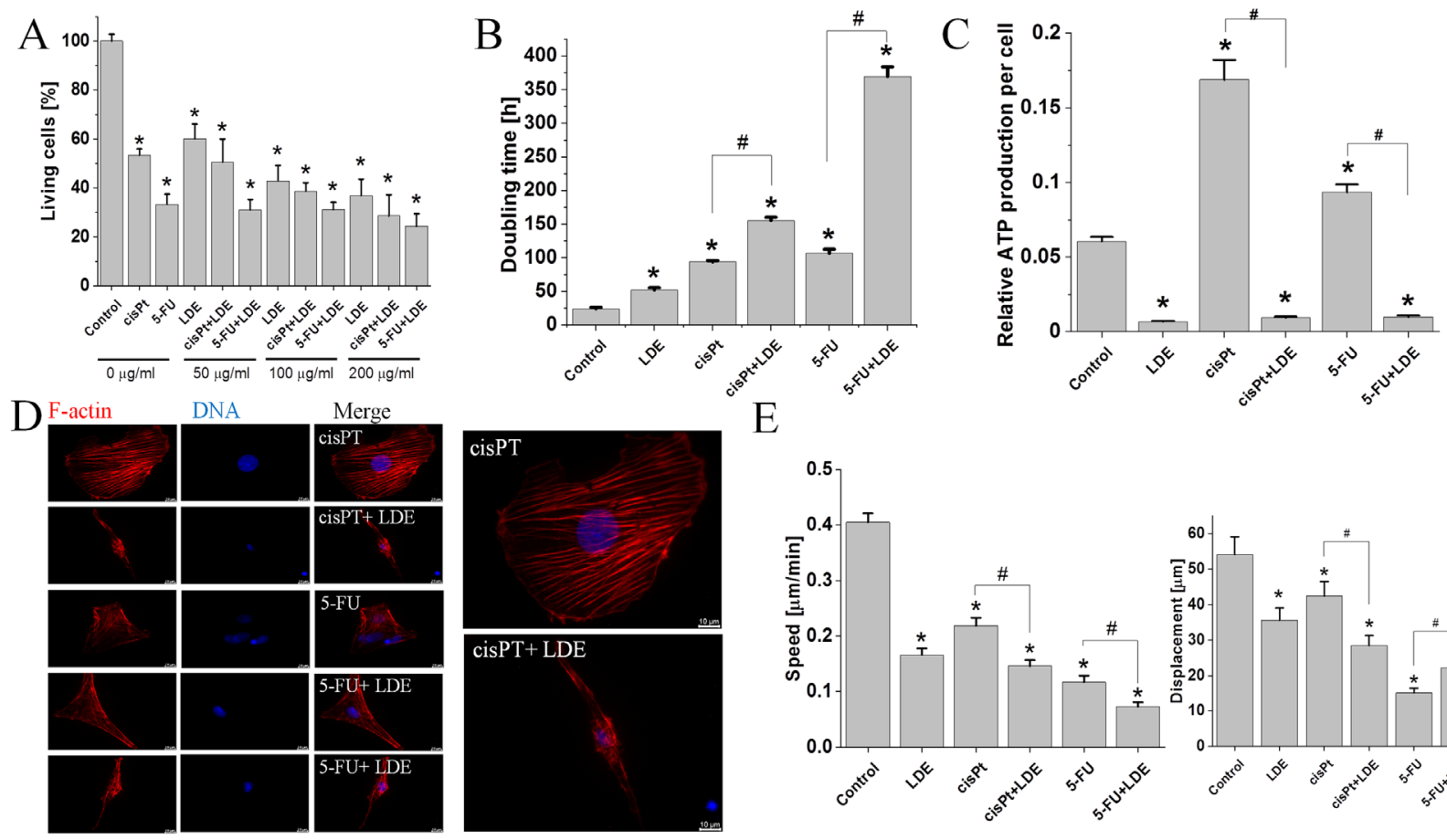

$\mathrm{E}$

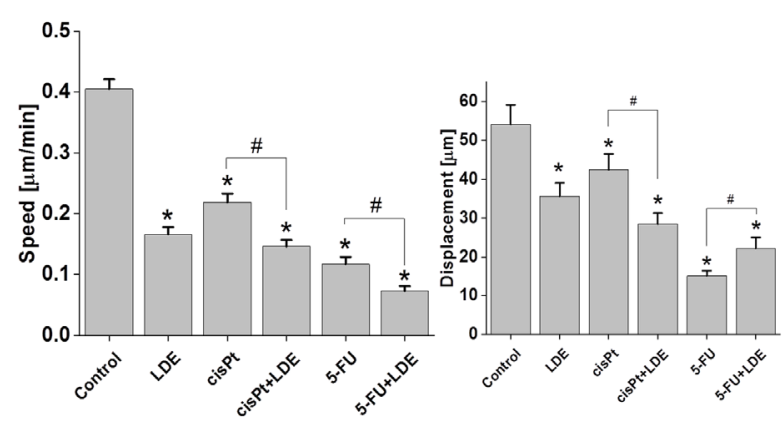

Figure 6. Effect of LDE on the sensitivity of AGS ce lls to cytostatics.

(A) AGS cells were cultivated in the presence of $200 \mu \mathrm{g} / \mathrm{ml}$ LDE and cytostatics, and their survival rate was estimated after 48 hours with Trypan blue assay. (B) AGS cells were incubated as in A and their proliferation was estimated in the next 24-96 hours with Coulter Counter to calculate the population doubling times. (C) Cells were seeded at a density of 2000 cells/well in 12 -well plates and incubated for 24 hours before administration of LDE and analyses of ATP levels. (D) Actin cytoskeleton architecture of AGS cells under control conditions (left) and in the presence of $200 \mu \mathrm{g} / \mathrm{ml} /$ cytostatics (F-actin-red, DNA-blue). Scale bar - $50 \mu \mathrm{m}$. (E) Cells were treated as in A and their motility was estimated with time-lapse video microscopy. Circular diagrams and dot-plots show trajectories and movement parameters (distance and displacement) at a single cell level. Statistical significance was calculated with ANOVA/non-parametric Mann-Whitney test, ${ }^{*} p<0.05$ vs control. Data representative for 3 independent experiments. Note that LDE increases sensitivity of AGS cells to cytostatics. 
Table 1. Organic compounds and bioelements in extracts from Lactarius deterrimus fruiting bodies [mg/100 $\mathrm{g}$ dry weight]

Lactarius deterrimus fruiting bodies

Phenolic compounds

\begin{tabular}{ll}
\hline p-Hydroxybenzoic acid & $4.67 \pm 0.33^{\mathrm{a}}$ \\
\hline Phenyloalanine & $220.1 \pm 33.12^{\mathrm{b}}$ \\
\hline Cinnamic acid & $1.61 \pm 0.14^{\mathrm{a}, \mathrm{b}, \mathrm{c}}$ \\
\hline Catechin & $165.8 \pm 12.5^{\mathrm{a} . \mathrm{b} . c}$ \\
\hline
\end{tabular}

Sterols

\begin{tabular}{ll}
\hline Ergosterol & $22.05 \pm 0.18$ \\
\hline Ergosterol peroxide & $23.15 \pm 5.79$ \\
\hline
\end{tabular}

Indole compounds

\begin{tabular}{ll}
\hline L-tryptophan & $8.05 \pm 0.52^{\mathrm{a}}$ \\
\hline Tryptamine & $6.56 \pm 0.02^{\mathrm{a}, \mathrm{b}}$ \\
\hline 5-Hydroxy-L-tryptophan & $0.31 \pm 0.01^{\mathrm{a}, \mathrm{b}}$ \\
\hline
\end{tabular}

Bioelements

\begin{tabular}{ll}
\hline $\mathrm{Ca}$ & $456 \pm 27^{\mathrm{a}}$ \\
\hline $\mathrm{Cd}$ & $3.19 \pm 0.31^{\mathrm{a}, \mathrm{b}}$ \\
\hline $\mathrm{Cu}$ & $0.82 \pm 0.02^{\mathrm{a}, \mathrm{c}}$ \\
\hline $\mathrm{Fe}$ & $4.28 \pm 0.02^{\mathrm{a}, \mathrm{d}}$ \\
\hline $\mathrm{K}$ & $623 \pm 44 \mathrm{a}, \mathrm{b}, \mathrm{c}, \mathrm{d}, \mathrm{e}$ \\
\hline $\mathrm{Na}$ & $942 \pm 38^{\mathrm{a}, \mathrm{b}, \mathrm{c}, \mathrm{d}, \mathrm{e}, \mathrm{f}}$ \\
\hline $\mathrm{Mg}$ & $435 \pm 15^{\mathrm{b}, \mathrm{c}, \mathrm{d}, \mathrm{e}, \mathrm{f}, \mathrm{g}}$ \\
\hline $\mathrm{Pb}$ & $4.94 \pm 0.02^{\mathrm{a}, \mathrm{e}, \mathrm{f}, \mathrm{g}}$ \\
\hline $\mathrm{Zn}$ & $11.56 \pm 1.16^{\mathrm{a}, \mathrm{e}, \mathrm{f}, \mathrm{g}}$ \\
\hline
\end{tabular}

*under the limit of detection; values marked with $(a, b, c, d, e, f, g)$ within the same row are significantly different $(p<0.05) ; \mathrm{N}=6$

ing bodies of $L$. deterrimus are also rich in bioelements. High concentrations of potassium, sodium, magnesium, calcium, zinc and iron were detected in the HPLC assay. Notably, they were accompanied by relatively high levels of heavy metals, including copper, cadmium and lead. Because anticancer action of organic compounds was demonstrated in numerous cellular models, these data indicate that the anti-cancer potential of LDE is related to the network of synergistic effects of bioactive LDE compounds. On the other hand, attention must be paid to environmental factors that can result in accumulation of heavy ions.

\section{Synergy of LDE with 5-FU and cisPt in their action on AGS cells}

Finally, we focused our attention on the effect of LDE on the effective doses of chemotherapeutics. LDE $(200 \mu \mathrm{g} / \mathrm{ml})$ enhanced the cytostatic effect of cisplatin (cisPt) and 5-fluorouracil (5-FU). This is illustrated by synergy of the inhibitory effects of LDE (especially at $50 \mu \mathrm{g} / \mathrm{ml}$ ) and cytostatics (especially $5-\mathrm{FU}$ ) on AGS viability/metabolism (Fig. 6A). Concomitantly, the synergy of cytostatic effects of LDE and both tested drugs has been confirmed by increased AGS doubling times under the double-drug stress (Fig. 6B). The combined LDE/5FU treatment was more effective than $\mathrm{LDE} / \mathrm{cisPt}$ administration. Even though increased ATP production was observed in cisplatin and 5-fluorouracil-treated cells (Fig. 6C), the cells that underwent double-treatment displayed a reduction in the ATP levels. These effects were also correlated with shifts in the morphology/cytoskeleton architecture and inhibition of AGS motility (Fig. 6D, E).

Collectively, our data indicate that LDE can increase sensitivity of AGS to chemotherapeutics, presumably through ROS-related interference with ATP production.

\section{DISCUSSION}

Till now, research on application of mushrooms in cancer treatment was predominantly undertaken in the Asian countries and concerned Asian mushroom species, pinpointing some of them as a potential source of anti-cancer agents. For instance, Agaricus blazei extract increases NK cell activity and reduces chemotherapyassociated side effects (Ahn et al., 2004). Similarly, the extract from Grifola frondosa (Maitake) has been shown to induce apoptosis of breast cancer cells by Bak-1 gene activation (Soares et al., 2011). Cordyceps (Khan et al., 2018) and Coriolus versicolor compounds exert cytostatic effects on cancer cells while stimulating activity of immune cells (Cui \& Chisti, 2003). Therefore, Krestin (prepared on the basis of polysaccharide $\mathrm{K}$ ) has been approved for supplementation of cancer chemotherapy and radiotherapy (Tsukagoshi et al., 1984). All of these capacities are related to the activity of the active compounds and bioelements present in the mushroom extracts. Our study is perhaps the first to focus on the anti-cancer activity of a mushroom from Eastern Europe. It shows strong and dose-dependent cytostatic/cytotoxic effects of the phenolics/sterol-rich Lactarius deterrimus extract (LDE) on gastric cancer cells, which apparently depend on LDEinduced, ROS-mediated mitochondrial dysfunction. Concomitant synergy of its effects with chemotherapeutics confirms that LDE can be used as a supplement for traditional strategies of gastric cancer chemotherapy.

In our hands, LDE inhibited proliferation of AGS cells and decreased their viability. Due to the significance of both parameters for cancer promotion, these data indicate that LDE can be helpful in delaying the outgrowth of gastric tumors. Cytostatic effects of LDE were accompanied by inhibition of gastric cancer cell motility; thereby LDE apparently reduces AGS invasive and metastatic potential, thus potentially interfering with gastric cancer progression. Actin polymerization/depolymerization cycles allow for continuous turn-over of actin filaments, crucial for cell migration and for penetration of the tissue barriers (Pollard, 1986). Induction of cytoskeleton rearrangements by LDE, which is illustrated by a reduced number of stress fibers in AGS cells, indicates that the LDE compounds may act similarly to the other compounds that selectively affect cancer cells' cytoskeleton. For instance, cytochalasin D (isolated from Metarrbizium sp.) is known to disorganize the actin cytoskeleton and to induce expression of E-cadherin. Thus, it can interfere with EMT (epithelial-mesenchymal transition) of cancer cells (Shankar \& Nabi, 2015). Additionally, these compounds predominantly affect malignant cancer cells, while remaining relatively neutral to normal epithelial and immune cells (Trendowski, 2015). In our hands, cytostat- 
ic effects of LDE on normal gastric fibroblasts were less intense than in cancer cell populations and were observable at the highest LDE concentrations. These data are in agreement with other observations on the reactivity of normal cells to phytochemicals. For instance, curcumin inhibits normal cell proliferation (Jackson et al., 2013), but this activity does not deny its therapeutic potential. In the stomach systems, stromal fibroblasts play a crucial role in formulation of the gastric cancer microenvironment (Krzysiek-Mączka et al., 2018; Krzysiek-Mączka et al., 2019; Krzysiek-Mączka et al., 2020). LDE can interfere with this activity of cancer-associated fibroblasts but whether these benefits outweigh the side effects of LDE requires further (in vivo) study. In any case, we show that the LDE compounds may not only delay gastric cancer development but also reduce its invasiveness/malignancy.

Further studies revealed a reduced ATP production in the LDE-treated AGS cells, which was correlated with their attenuated metabolic activity (estimated by MTT test) and with intensified autophagy. Normally, intrinsic or stress-induced autophagy eliminates damaged/excessive organelles from the cells. In cancer systems, autophagy may thus enhance cellular drug-resistance (Sui et al., 2013; Li et al., 2019). However, the imbalance between catabolic processes during autophagy (mainly allowing for cell survival) and cell metabolism (Mathew et al., 2007; Levy \& Thorburn, 2020) may also result in cell apoptosis. In our hands, autophagic responses are apparently not sufficient for AGS cells to survive the LDE stress, even though we observed discrete AGS subpopulations characterized by different levels of ROS. Consequently, $L$. deterrimus extracts deteriorate gastric cancer cells' welfare (Chaabane et al., 2013).

Our mechanistic analyses revealed generally increased calcium and ROS levels, and the signs of mitochondrial stress, in particular mitochondrial fusions in the LDE-treated AGS cells. This points to the dysfunction of oxidative phosphorylation (OXPHOS) machinery as a possible primary source of the observed cytostatic/ cytotoxic effects of LDE. Mitochondria are crucial for many cellular processes, including metabolism, calcium homeostasis, proliferation, differentiation, migration or apoptosis (Zhao et al., 2013). Calcium fluxes from mitochondria and/or from the endoplasmatic reticulum may initiate activation of signaling pathways that further lead to cell death under the LDE stress (Clapham et al., 1995; Danese et al., 2017). Whereas the mitochondrial fission might increase invasive potential of cancer cells, mitochondrial fusion under stressful conditions is thought to allow them to adapt to stress conditions, including $\mathrm{mtD}$ NA damage. In agreement with our data, mitochondrial fusion participates in cellular adaptation to stress, inhibits cell proliferation and intensifies autophagy in the cancer cells (Grandemange et al., 2009). Previously, over-expression of mitofusins has been also demonstrated to inhibit cell apoptosis (Chan, 2006; Santin et al., 2013; MiretCasalas et al., 2018). Because we observed the signs of mitofusion in LDE-treated populations, this process can represent an adaptation mechanism which helps the cells to at least survive the short-term LDE stress. However, low viability of long-term LDE-treated AGS cells confirms that these defense mechanisms are insufficient to fully counteract the LDE stress.

Until the end of the 20th century, stomach cancer was a predominant cancer type among men in Poland. Nowadays, it is less common than the lung, prostate and colon tumors. On the other hand, morbidity due to stomach cancer in Poland is 25\% higher than in the Eu- ropean Union. Whereas therapeutic approaches against early-diagnosed tumor practically guarantee full recovery, chemotherapy of malignant tumors does not give sufficient effects because only $14 \%$ of patients survive 5 years after diagnosis (Polish National Cancer Registry). These facts justify the search for new gastric cancer treatment strategies. Collectively, our data show an efficient antigastric cancer action of LDE in vitro that is mediated by mitochondrial ROS and remains insensitive to the cellular self-defense systems that depend on mitochondrial fusion and autophagy. Not surprisingly, these activities of LDE were translated into additive/synergic effects with chemotherapeutic agents that are commonly used in the gastric cancer therapy. In fact, LDE increased the action of 5-fluorouracil and cisplatin (Hohenberger \& Gretschel, 2003; Efferth \& Koch, 2011). Notwithstanding the environmental factors that can affect LDE composition (including concentrations of heavy ions) and limit their pharmaceutical potential, our data underline the potential of LDE extracts for supplementation of standard chemotherapeutic approaches.

\section{LIMITATIONS AND OUTLOOK}

Plant extracts represent complex mixtures of organic substances and simple chemical compounds. Although mushrooms are rich in chemical compounds that can be used for versatile purposes (including cancer treatment), their therapeutic potential is still underestimated. This may result from the relative lack of knowledge (i) on the specific compounds responsible for the potential anti-cancer properties of the mushroom extract; (ii) interactions between these compounds enhancing/deteriorating their biological activities, (iii) their bioavailability and (iv) interactions of these compounds with existing cancer therapies. Our studies show that the compounds from $L$. deterrimus extracts exert cytostatic, cytotoxic and anti-invasive effects on the gastric cancer cells in vitro. Together with the observed synergy of LDE and cisplatin/5-fluorouracil effects on AGS cells our data show the potential of LDE as a supplement in traditional chemotherapy strategies of gastric cancer treatment. Additive/synergic effects exerted by these compounds may rely on their functional cooperation; for instance, perforation of the cell membranes by one compound, followed by intracellular action of other compounds (Efferth \& Koch, 2011). Potentially, they may increase the efficiency of other individually targeted therapies, thus reducing their adverse effects. On the other hand, there are several restrictions that should be considered when assessing the consequences of this study. First, the in vitro data must be confirmed by ex vivo/in vivo animal models. Furthermore, the bioavailability of LDE compounds in the gastric cancer niches requires experimental verification. An open question remains whether mushrooms can exert similar (homeopatic) effects when taken with everyday diet or if their activity is restricted to the EtOH extracts. Potentially, the epidemiologic data on the possible correlation between $L$. deterrimus consumption and gastric cancer incidence would add to its recognition as a potentially valuable diet component. Last but not least, accumulation of heavy ions may be limiting for pharmaceutical applications of this species. Accordingly, its fruiting bodies must be collected from non-polluted places or produced by biotechnological methods. Further studies on these topics are crucial for extending the promising perspective of $L$. deterrimus application in cancer prevention. 


\section{Author Contributions}

Conceptualization, Kamila Król, Damian Ryszawy; Data curation, Kamila Król, Maciej Pudełek, Damian Ryszawy; Funding acquisition, Damian Ryszawy; Investigation, Kamila Król, Bożena Muszyńska, Katarzyna Sułkowska-Ziaja, Agata Krakowska, Maciej Pudełek, Damian Ryszawy; Methodology, Bożena Muszyńska, Damian Ryszawy; Project administration, Damian Ryszawy, Jarosław Czyż; Resources, Gracjana Krzysiek-Mączka, Mateusz Wierdak, Damian Ryszawy; Supervision, Damian Ryszawy and Jarosław Czyż; Validation, Kamila Król; Visualization, Kamila Król, Maciej Pudełek, Damian Ryszawy; Writing - original draft, Kamila Król; Writing - review \& editing, Kamila Król, Maciej Pudełek, Bożena Muszyńska and Jarosław Czyż.

\section{Data Availability Statement}

The data that supports the findings of this study are available from the corresponding author upon reasonable request.

\section{Conflicts of Interest}

The authors declare no conflict of interest.

\section{Acknowledgements}

We wish to thank Dr. Elżbieta Karnas and Professor Ewa Zuba-Surma for technical support with ImageStreamX analysis.

\section{REFERENCES}

Ahn WS, Kim DJ, Chae GT, Lee JM, Bae SM, Sin JI, Kim YW, Namkoong SE, Lee IP (2004) Natural killer cell activity and quality of life were improved by consumption of a mushroom extract, Agaricus blazei Murill Kyowa, in gynecological cancer patients undergoing chemotherapy. Int J Gynecol Cancer 14: 589-594. https://doi. org/10.1111/j.1048-891X.2004.14403.x

Bergendorff O, Sterner O (1988) The sesquiterpenes of Lactarius deliciosus and Lactarius deterrimus. Phytochemistry 27.1: 97-100. https://doi. org/10.1016/0031-9422(88)80597-1

Brenner H, Rothenbacher D, Arndt V (2009) Epidemiology of stomach cancer. Cancer Epidemiol 472: 467-477. https://doi.org/10.1007/9781-60327-492-0_23

Bray F, Ferlay J, Soerjomataram I, Siegel RL, Torre LA, Jemal A (2018) Global cancer statistics 2018: GLOBOCAN estimates of incidence and mortality worldwide for 36 cancers in 185 countries. CA Cancer J Clin 68: 394-424. https://doi.org/10.3322/caac.21492

Chaabane W, User SD, El-Gazzah M, Jaksik R, Sajjadi E, RzeszowskaWolny J, Los MJ (2013) Autophagy, apoptosis, mitoptosis and necrosis: interdependence between those pathways and effects on cancer. Archiv Immunol Ther Exp 61: 43-58. https://doi.org/10.1007/ s00005-012-0205-y

Chan DC (2006) Mitochondrial fusion and fission in mammals. Annu Rev Cell De Biol 22: 79-99. https://doi.org/10.1146/annurev.cellbio.22.010305.104638

Chatterjee S, Sarma MK, Deb U, Steinhauser G, Walther C, Gupta DK (2017) Mushrooms: from nutrition to mycoremediation. Env Sci Pollut Res 24: 19480-19493. https://doi.org/10.1007/s11356-0179826-3

Clapham DE (1995) Calcium signaling. Cell 80: 259-268. https://doi. org/10.1016/0092-8674(95)90408-5

Cui J, Chisti Y (2003) Polysaccharopeptides of Coriolus versicolor: physiological activity, uses, and production. Biotech Adv 21: 109-122. https://doi.org/10.1016/S0734-9750(03)00002-8

Danese A, Patergnani S, Bonora M, Wieckowski MR, Previati M, Giorgi C, Pinton P. Calcium regulates cell death in cancer: Roles of the mitochondria and mitochondria-associated membranes (MAMs) (2017) Biochim Biophys Acta Bioenergetics 1858: 615-627. https://doi. org/10.1016/j.bbabio.2017.01.003

Dulger B, Yilmaz F, Gucin F (2002) Antimicrobial activity of some Lactarius species. Pharm Biol 40: 304-306. https://doi.org/10.1076/ phbi.40.4.304.8468

Efferth T, Koch E (2011) Complex interactions between phytochemicals. The multi-target therapeutic concept of phytotherapy. Curr Drug Targets 12: 122-132. https://doi.org/10.2174/138945011793591626
Giollant M, Guillot J, Damez M, Dusser M, Didier P, Didier E (1993) Characterization of a lectin from Lactarius deterrimus (research on the possible involvement of the fungal lectin in recognition between mushroom and spruce during the early stages of mycorrhizae formation). Plant Physiol 101: 513-522. https://doi.org/10.1104/ pp.101.2.513

Gomes A, Bhattacharjee P, Mishra R, Biswas AK, Dasgupta SC, Giri B (2010) Anticancer potential of animal venoms and toxins. Indian $J$ ExpBiol 48: 93-103

Grandemange S, Herzig S, Martinou JC (2009) Mitochondrial dynamics and cancer. In Seminars in Cancer Biology, vol 19, no 1, pp 50-56. Academic Press. https://doi.org/10.1016/j.semcancer.2008.12.001

Grdović N, Dinić S, Arambašić J, Mihailović M, Uskoković A, Marković J, Poznanović G, Vidović S, Zeković Z, Mujić A, Mujić I, Vidaković M (2012) The protective effect of a mix of Lactarius deterrimus and Castanea sativa extracts on streptozotocin-induced oxidative stress and pancreatic $\beta$-cell death. Br J Nutr 108: 1163-1176. https://doi.org/10.1017/S0007114511006702.

Habtemariam S. (2020) Trametes versicolor (Synn. Coriolus versicolor) Polysaccharides in cancer therapy: targets and efficacy. Biomedicines 8: 135. https://doi.org/10.3390/biomedicines 8050135

Hashemi SA, Abediankenari S, Ghasemi M, Azadbakht M, Yousefzadeh Y, and Dehpour, A A (2011) The effect of fig tree latex (Ficus carica) on stomach cancer line. Iran Red Crescent Med J 13: 272

Hohenberger P, Gretschel S (2003) Gastic cancer. Lancet 362: 305-315. https:/ /doi.org/10.1016/S0140-6736(03)13975-X.

Ijaz S, Akhtar N, Khan MS, Hameed A, Irfan M, Arshad MA, Ali S, Asrar M (2018) Plant derived anticancer agents: A green approach towards skin cancers. Biomed Pharmacother 103: 1643-1651. https:// doi.org/10.1016/j.biopha.2018.04.113

Jackson SJ, Murphy LL, Venema RC, Singletary KW, Young AJ (2013) Curcumin binds tubulin, induces mitotic catastrophe, and impedes normal endothelial cell proliferation. Food Chem Toxicol 60: 431-438. https://doi.org/10.1016/j.fct.2013.08.008

Jain D, Kumar S (2012) Snake venom: a potent anticancer agent. Asian Pacific J Cancer Prev 13: 4855-4860. https://doi.org/10.7314/APJCP.2012.13.10.4855

Kang JH, Jang JE, Mishra SK, Lee H J, Nho CW, Shin D, Jin M, Kim MK, Choi C, Oh SH (2015) Ergosterol peroxide from Chaga mushroom (Inonotus obliquus) exhibits anti-cancer activity by down-regulation of the $\beta$-catenin pathway in colorectal cancer. J Ethnopharmacol 173: 303-312. https://doi.org/10.1016/j.jep.2015.07.030

Krzysiek-Maczka G, Targosz A, Szczyrk U, Wrobel T, Strzalka M, Brzozowski T, Czyz J, Ptak-Belowska A (2020) Long-term Helicobacter pylori infection switches gastric epithelium reprogramming towards cancer stem cell-related differentiation program in $\mathrm{Hp}$-activated gastric fibroblast-TGF $\beta$ dependent manner. Microorganisms 8: 1519. https://doi.org/10.3390/microorganisms8101519

Krzysiek-Maczka G, Wrobel T, Targosz A, Szczyrk U, Strzalka M, Ptak-Belowska A, Czyz J, Brzozowski T (2019) Helicobacter pylori-activated gastric fibroblasts induce epithelial-mesenchymal transition of gastric epithelial cells in vitro in a TGFß-dependent manner. Helicobacter 24: e12653. https://doi.org/10.1111/hel.12653

Krzysiek-Maczka G, Targosz A, Szczyrk U, Strzałka M, Sliwowski Z, Brzozowski T, Czyz J, Ptak-Belowska A (2018) Role of Helicobacter pylori infection in cancer-associated fibroblast-induced epithelial-mesenchymal transition in vitro. Helicobacter 23: e12538. https://doi. org $/ 10.1111 /$ hel.12538

Mulcahy Levy JM, Thorburn A (2020) Autophagy in cancer: moving from understanding mechanism to improving therapy responses in patients. Cell Death Differ 27: 843-857. https://doi.org/10.1038/ s41418-019-0474-7

Li YJ, Lei YH, Yao N, Wang CR, Hu N, Ye WC, Zhang DM, Chen ZS (2017) Autophagy and multidrug resistance in cancer. Chinese J Cancer 36: 1-10. https://doi.org/10.1186/s40880-017-0219-2

Li X, Zhou Y, Li Y, Yang L, Ma Y, Peng X, Yang S, Liu J, Li H (2019) Autophagy: A novel mechanism of chemoresistance in cancers. Biomed Pharmacother 119: 109415. https://doi.org/10.1016/j.biopha.2019.109415

Lichota A, Gwozdzinski K (2018) Anticancer activity of natural compounds from plant and marine environment. Int J Mol Sci 19: 3533. https://doi.org/10.3390/ijms19113533

Liu L, Hudgins WR, Shack S, Yin MQ and Samid,D (1995) Cinnamic acid: a natural product with potential use in cancer intervention. Int J Cancer 62: 345-350. https://doi.org/10.1002/ijc.2910620319

Mathew R, Karantza-Wadsworth V, White E (2007) Role of autophagy in cancer. Nat Rev Cancer 7: 961-967. https://doi.org/10.1038/ nrc 2254

Mihailović M, Arambašić Jovanović J, Uskoković A, Grdović N, Dinić S, Vidović S, Poznanović G, Mujić I, Vidaković M (2015) Protective effects of the mushroom Lactarius deterrimus extract on systemic oxidative stress and pancreatic islets in streptozotocin-induced diabetic rats. I Diabetes Res 576726. https://doi.org/10.1155/2015/576726

Miret-Casals L, Sebastián D, Brea J, Rico-Leo EM, Palacín M, Fernández-Salguero PM, Loza MI, Albericio F, Zorzano A (2018) Identification of new activators of mitochondrial fusion reveals a link 
between mitochondrial morphology and pyrimidine metabolism. Cell Chem Biol 25: 268-278. https://doi.org/10.1016/j.chembiol.2017.12.001

Muszyńska B, Kała K, Włodarczyk A, Krakowska A, Ostachowicz B, Gdula-Argasinska J, Suchocki P (2020) Lentinula edodes as a source of bioelements released into artificial digestive juices and potential anti-inflammatory material. Biol Trace Element Res 194: 603-613. https://doi.org/10.1007/s12011-019-01782-8

Muszynska B (2007) Analysis of indole compounds and nitric bases in fruiting bodies of Lactarius deterrimus by TLC. I Planar Chromatogr Mod TLC 20: 55-58. https://doi.org/10.1556/JPC.20.2007.1.9

Muszyńska B, Łojewski M, Rojowski J, Opoka W, and Sułkowska-Ziaja K (2015) Natural products of relevance in the prevention and supportive treatment of depression. Psychiatr Pol 49: 435-453. https:// doi.org/10.12740/pp/29367

Nuytinck J, Verbeken A (2005) Morphology and taxonomy of the European species in Lactarius sect. Deliciosi (Russulales) Mycotaxon 92 125-168. https://doi.org/10.1139/cib-2014-0102

Passamonti S, Vrhovsek U, Vanzo A, Mattivi F (2003) The stomach as a site for anthocyanins absorption from food. FEBS Lett 544: 210-213. https://doi.org/10.1016/S0014-5793(03)00504-0

Pollard TD (1986) Rate constants for the reactions of ATP-and ADP-actin with the ends of actin filaments. J Cell Biol 103: 27472754. https://doi.org/10.1083/jcb.103.6.2747

Pudełek M, Catapano J, Kochanowski P, Mrowiec K, Janik-Olchawa N, Czyż J, Ryszawy D (2019) Therapeutic potential of monoterpene $\alpha$-thujone, the main compound of Thuja occidentalis L. essential oil, against malignant glioblastoma multiforme cells in vitro. Fitoterapia 134: 172-181. https://doi.org/10.1016/j.fitote.2019.02.020

Rayan A, Raiyn J, Falah M (2017) Nature is the best source of anticancer drugs: Indexing natural products for their anticancer bioactivity. PloS One 12: e0187925. https://doi.org/10.1371/journal. pone. 0187925

Riihimäki M, Hemminki A, Sundquist K, Sundquist J, Hemminki K (2016) Metastatic spread in patients with gastric cancer. Oncotarget 7: 52307. https://doi.org/10.18632/oncotarget.10740

Ryszawy D, Pudełek M, Catapano J, CiarachM., Setkowicz Z Konduracka, E, Madeja Z, Czyż J (2019a) High doses of sodium ascorbate interfere with the expansion of glioblastoma multiforme cells in vitro and in vivo. Life Sci. 232: 116657. https://doi.org/10.1016/j. lfs.2019.116657

Ryszawy D, Pudełek M, Kochanowski P, Janik-Olchawa N, Bogusz J, Rapała M, Koczurkiewicz P, Mikołajczyk J Borek I, Kędracka-Krok S, Karnas E, Zuba-Surma E, Madeja Z, Czyż J (2019b) High bisphenol A concentrations augment the invasiveness of tumor cells through Snail-1/Cx43/ERR $\gamma$-dependent epithelial-mesenchymal transition. Toxicol in Vitro 62: 104676. https://doi.org/10.1016/j. tiv.2019.104676

Santin G, Piccolini VM, Barni S, Veneroni P, Giansanti V, Dal Bo V, Bernocchi G, Bottone MG (2013) Mitochondrial fusion: a mechanism of cisplatin-induced resistance in neuroblastoma cells? Neurotoxicol 34: 51-60. https://doi.org/doi: 10.1016/j.neuro.2012.10.011

Sarikurkcu C, Tepe B, Yamac M (2008) Evaluation of the antioxidant activity of four edible mushrooms from the Central Anatolia, Eskisehir - Turkey: Lactarius deterrimus, Suillus collitinus, Boletus edulis, Xerocomus chrysenteron. Biores Tech 99: 6651-6655. https://doi. org/10.1016/j.biortech.2007.11.062

Shankar J, Nabi IR (2015) Actin cytoskeleton regulation of epithelial mesenchymal transition in metastatic cancer cells. PloS One 10: e0119954. https://doi.org/10.1371/journal.pone.0119954

Shrestha G, Clair LLS (2013) Lichens: a promising source of antibiotic and anticancer drugs. Phytochem Rev 12: 229-244. https://doi. org/10.1007/s11101-013-9283-7

Smyth EC, Nilsson M, Grabsch HI, van Grieken NC, Lordick F (2020) Gastric cancer. Lancet 396: 635-648. https://doi.org/10.1016/ S0140-6736(20)31288-5

Soares R, Meireles M, Rocha A, Pirraco A, Obiol D, Alonso E, Joos G, Balogh G (2011) Maitake (D fraction) mushroom extract induces apoptosis in breast cancer cells by BAK-1 gene activation. J Med Food 14: 563-572. https://doi.org/10.1089/imf.2010.0095

Sobolewska A, Dunisławska A, Stadnicka K (2021) Natural substances in cancer - do they work? Phys Sci Rev 2021: 000010151520190060. https://doi.org/10.1515/psr-2019-0060

Song MY, Lee DY, Kim EH (2020) Anti-inflammatory and anti-oxidative effect of Korean propolis on Helicobacter pylori-induced gastric damage in vitro. I Microbiol 58: 878-885. https://doi.org/10.1007/ 12275-020-0277-z

Sroka J, Antosik A, Czyz J, Nalvarte I, Olsson J M, Spyrou G, Madeja Z (2007) Overexpression of thioredoxin reductase 1 inhibits migration of HEK-293 cells. Biol Cell 99: 677-687. https://doi. org/10.1042/bc20070024

Sui X, Chen R, Wang Z, Huang Z, Kong N, Zhang M, Han W, Lou F, Yang J, Zhang Q, Wang X, He C, Pan H (2013) Autophagy and chemotherapy resistance: a promising therapeutic target for cancer treatment. Cell Death Dis 4: e838-e838. https://doi.org/10.1038/ cddis. 2013.350

Sułkowska-Ziaja K, Maślanka A, Szewczyk A, Muszyńska B (2017) Physiologically active compounds in four species of Phellinus. Natural Prod Comp 12: 1934578X1701200313. https://doi. org/10.1177/1934578x1701200313

Tan W, Pan M, Liu H, Tian H, Ye Q, Liu H (2017). Ergosterol peroxide inhibits ovarian cancer cell growth through multiple pathways. OncoTargets Ther 10: 3467. https:/ /doi.org/10.2147/OTT.S139009

The global challenge of cancer (2020) Nat Cancer 1: 1-2. https://doi. org/10.1038/s43018-019-0023-9

Trendowski M (2015) Using cytochalasins to improve current chemotherapeutic approaches. Anti-Cancer Agents Med Chem 15: 327-335. https://doi.org/10.2174/1871520614666141016164335

Tsukagoshi S, Hashimoto Y, Fujii G, Kobayashi H, Nomoto K, Orita K (1984) Krestin (Psk). Cancer Treat Rev 11: 131-155. https://doi. org /10.1016/0305-7372(84)90005-7

You WC, Blot WJ, Chang YS, Ershow AG, Yang ZT, An Q, Henderson B, Xu GW, Fraumeni JF Jr, Wang TG (1988) Diet and high risk of stomach cancer in Shandong, China. Cancer Res 48: 35183523. https://doi.org/10.1016/0168-8510(90)90388-t

Zhao J, Zhang J, Yu M, Xie Y, Huang Y, Wolff DW, Abel PW, Tu $\mathrm{Y}$ (2013) Mitochondrial dynamics regulates migration and invasion of breast cancer cells. Oncogene 32: 4814-4824. https://doi. org/10.1038/onc.2012.494 